\title{
Design and Impact of Interactive Video Content for the Improvement of Student Engagement and Learning
}

\author{
R.Priyakanth ${ }^{1}$, Radha Abburi ${ }^{2}$, Manne Praveena ${ }^{3}$ \\ ${ }^{1,2,3}$ Department of ECE, BVRIT HYDERABAD College of Engineering for Women, Hyderabad, Telangana, India \\ 1 priyakanth.r@bvrithyderabad.edu.in \\ ${ }^{2}$ radha.a@bvrithyderabad.edu.in \\ ${ }^{3}$ praveena.m@bvrithyderabad.edu.in
}

\begin{abstract}
All over the world online education is offered now in all the streams. Numerous new technology courses in the form of video lectures are available online. However, in the engineering stream, questions arise about real learning. This study explores the new ways of making the video content more interactive in such a way that the learners will be active, engage themselves, participate, respond, and improve their thinking skills. Interactive video content can comprise a wide range of active elements, including questions, polls, interactive summaries, and many more. Including the interactive training videos in the learning management system (LMS) in any course may bring a lot of change in the learners' perspective of processing the attained knowledge. As a part of the study, the interactive videos on working in MATLAB environment were uploaded into the LMS portal of a lab course and the participation and engagement of around 120 learners was examined by the way the questions were answered. The questions in the form of case studies were given at middle to higher levels of learning classified by Bloom's Taxonomy. The attained learning outcomes measured indicated improvement in the learners' adaptation to new programming languages, skills they acquired in analyzing the case studies. New technologies like H5P etc for making interactive videos assuredly help in the acquisition and enhancement of new skill sets of the learner as evident in the observations. These interactions helps us in driving deeper engagement and transform the ways a learner thinks and processes the knowledge attained.
\end{abstract}

Keywords: Interactive Video, H5P, Student engagement, LMS, Direct Assessment, Real Learning.

\section{R.Priyakanth}

Department of ECE, BVRIT HYDERABAD College of Engineering for Women, Hyderabad, Telangana, India.

Priyakanth.r@bvrithyderabad.edu.in

\section{Introduction}

E-learning is growing into a gifted substitute to the conventional classroom education, serving the world to shift in the direction of all-time and stipulated learning. Usage of multimedia and technology not only helps the teacher to deliver the instruction, but also supports and assists the learners and present innovative forms of their assessment. Various new technologies embedded in the way of sharing knowledgeable content and insights lay a path towards the increased learner engagement, making the learner more responsible for learning, and improve the skills for independent and interdependent learning.

Course design is one of the structural factors for successful online student engagement (Orna Farrell and James Brunton, 2020). Knowledge sharing or course design in the form of videos is one of the affluent and influential approaches used in e-learning and these videos are the major academic resources to be added to any Learning Management System (LMS) (Brenda Juárez Santiago et al., 2020). This way of presenting the education for the learners has now become one of the striking and reliable methods. Including various interactions like questions, polls, interactive summaries etc makes a normal video lecture most interactive and helps us in driving deeper engagement and transform the ways a learner thinks and processes the knowledge attained. These interactions answered by the students can be assessed and the improvement in the attainment of learners' outcomes is achieved. Adding interactions in the form of hotspots in the video will convert a passive learner into an active learner (Sonia Wilkie et al., 2018).

In this paper the design of interactive videos using H5P integrated in the Moodle LMS is demystified. These interactive videos are prepared and uploaded into the LMS portal for "Basic Simulation" lab course wherein which the students will learn how to program using MATLAB. The impact of interactive videos on improvement in the student engagement and learning is observed on a set of 120 electronics and communication engineering students belonging to 2019 batch in their second year first semester. The same methodology is also used in "Electronic Devices and Circuits" and "Digital System Design" labs. The main motive is to make a learner more attentive and make him completely view the video to answer the interactions embedded in the video. This facilitates the teacher to assess the answers given by the learner in response to the interactions added and quantify the learners thinking skills. The interactions added to shorter videos rather than longer videos motivate the users and increase their intension to use and as an outcome high student engagement can be observed (Michail N. Giannakos et al., 2016).

\section{Interactive Videos Creation using H5P}

$\mathrm{H} 5 \mathrm{P}$ is a new free tool for creating rich interactive html5 learning content. They can be embedded into a number of different web platforms and LMS. The LMS platform we 
used for the creation of the course portal is Moodle. For the latest versions of Moodle LMS, H5P can be added directly into courses (L N Amali, N T Kadir, and M Latief, 2019). A content bank allows H5P to be created, edited and reused. H5P can also be connected to the grade book and supports activity completion.

Using H5P interactions can be added to the pre-recorded video. With an aim of creating new $\mathrm{H} 5 \mathrm{P}$ and adding it to the course, the teacher from the list of activities and resources, selects the type of activity as $\mathrm{H} 5 \mathrm{P}$ and creates it from the video content bank he can access. The teacher can also edit H5P files added to the course with the editing turned on. An option of attempt tracking is also available. This tracking can be used for calculating the final grade and also viewing his attempts hopefully aiming to do better next time.

In order to create various interactions to a video in Moodle LMS, the teacher need to select H5P interactive content in the list of activities as shown highlighted in the Fig.1.

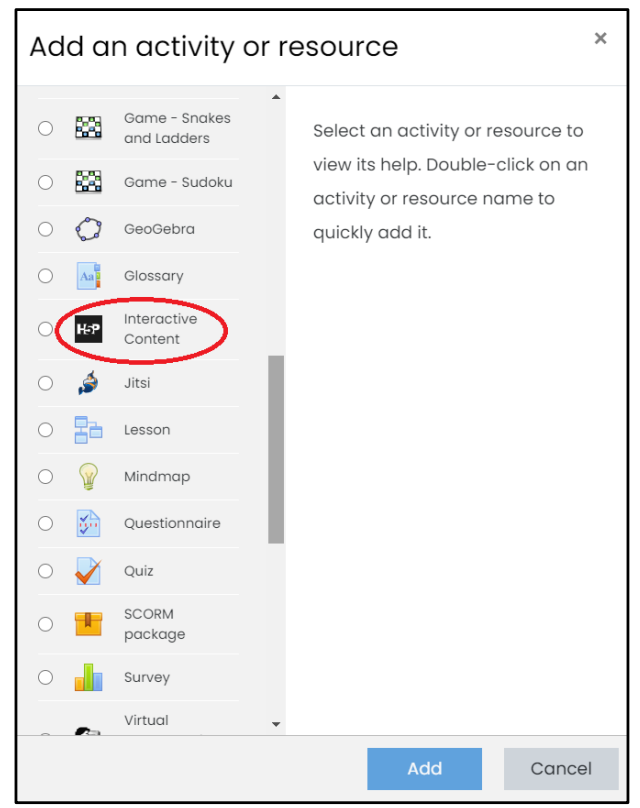

Fig. $1 \mathrm{H} 5 \mathrm{P}$ in the list of activities or resources

A list of H5P content type is listed in the next window. And with an aim of creating interactive video the teacher need to select the "Interactive Video" option as shown in Fig.2.

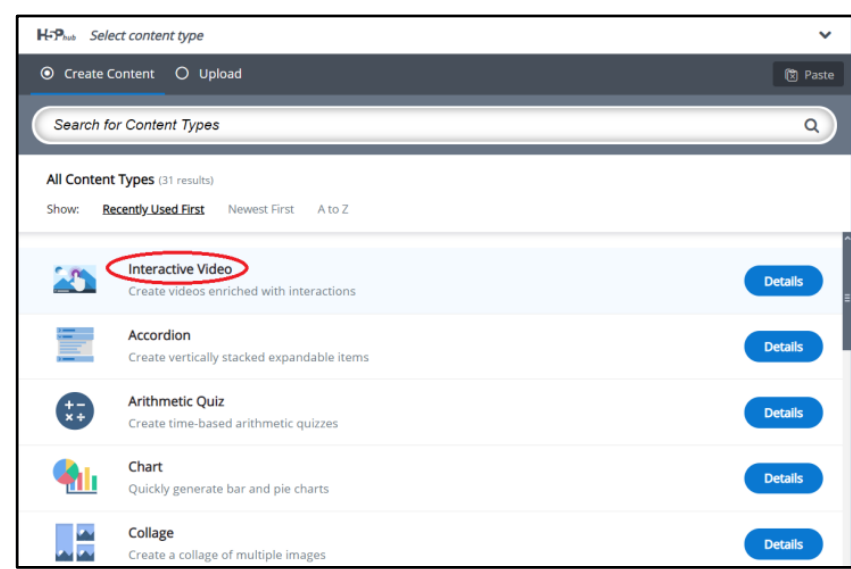

Fig. 2 Interactive video in the content type of H5P

Once the "Interactive video" is selected in the content type, the teacher can create the video with interactions in three steps as shown in Fig.3.

Step 1: Upload / embed video

Step 2: Add Interactions

Step 3: Summary task

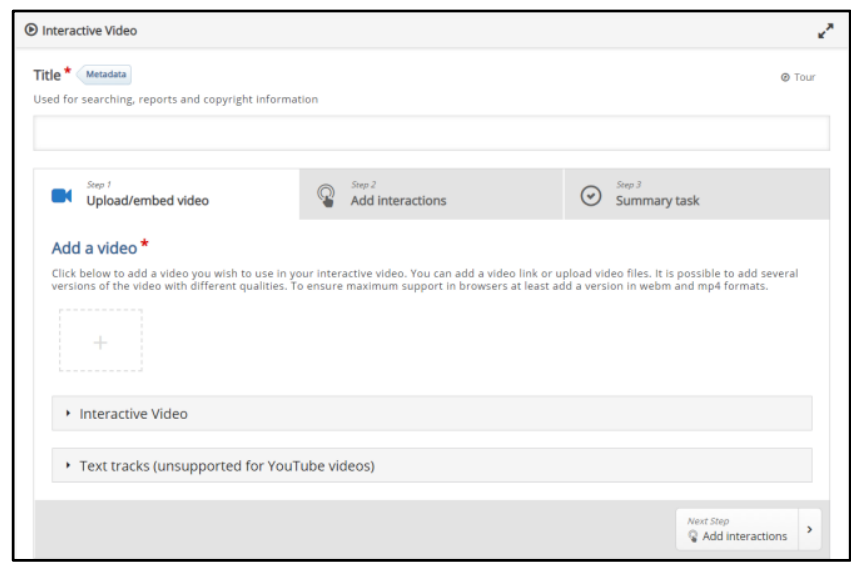

Fig. 3 Steps involved in creating interactive video content

The video for which interactions can be added be a prerecorded video or any YouTube video. The interactions that can be added to the video selected, could be a label, text, table, link, image, statements, single choice set questions, multiple choice questions, true / false, fill in the blanks, drag and drop, make the words, drag text, cross roads and navigation hotspot (Stefan Richtberg and Raimund Girwidz, 2019) as shown in Fig. 4 in the order from left to right inside the red box.

As an example "drag the words" interaction added to the video is shown in the Fig.5. The answerable interactions can be used for the assessment of the students. Various questions to test the learner's engagement can also be added in the summary. The interactions and the summary task questions can be assessed and added to the final grade in the course created in the institute's LMS portal.

Such an experience of remote teaching using interactive videos integrated in the LMS facilitates the learners in 
taking active roles for independent learning during the pandemic.

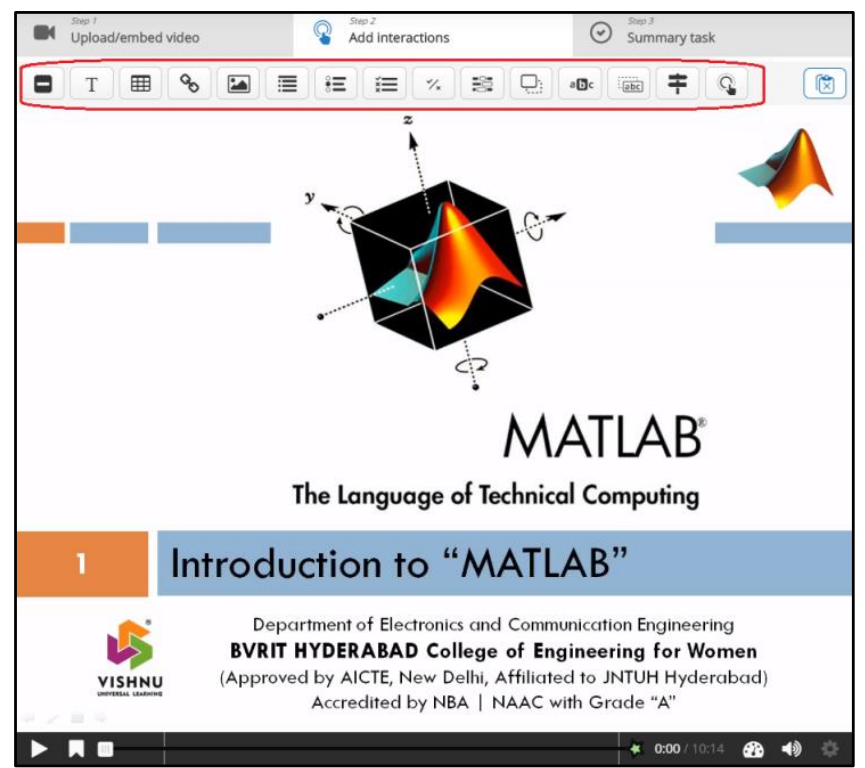

Fig. 4 Different types of interactions inside the red box

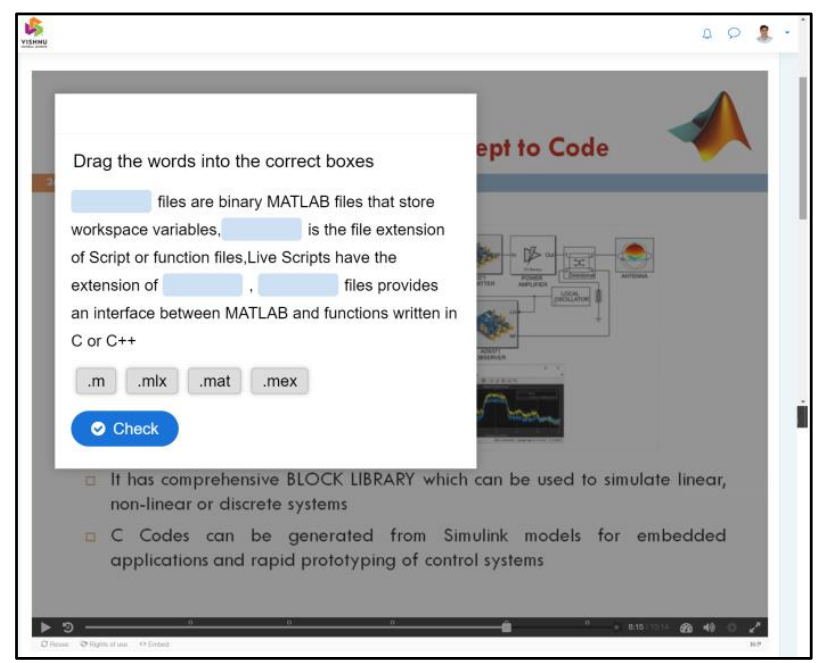

Fig. 5 Drag the words interaction added to the video

So many web based tools such as EduCanon, EduPuzzle, MediaSite, Camtasia Studio, HapYak, PopcornMaker etc exists using which interactive videos can be made (Line Kolås, 2015). The advantage of H5P plug-in into the LMS provides 31 different content types that can be used for enriching the course content in LMS.

\section{Experimental Study on Impact}

As a part of the study, the interactive videos on working in MATLAB environment were uploaded into the LMS portal of "Basic Simulation" lab course. This course is part of the second year of electronics and communication engineering. The participation and engagement of about 120 learners belonging to 2019 batch was examined by the way the questions were answered. The questions in the form of case studies were given at middle to higher levels of learning classified by Bloom's Taxonomy. Some questions in the interactive video done on the introduction to the lab were also given in the lower levels of Bloom's. The videos were paused, when an interaction in the form of pop-up questions appear and the teacher can provide the feedback for every question after the student answers the question (Marjolein E. Haagsman et al., 2020). The attained learning outcomes measured indicated improvement in the learners' adaptation to new programming languages. Since the current semester is going on, the assessment marks for only five interactive videos were considered in the study. Details of the interactive videos are shown in Table 1.

Table 1. Details of Interactive Videos

\begin{tabular}{|c|l|c|c|}
\hline Video & Description of Video & $\begin{array}{c}\text { No. of } \\
\text { Interactions }\end{array}$ & $\begin{array}{c}\text { Assessment } \\
\text { Marks }\end{array}$ \\
\hline 1 & $\begin{array}{l}\text { Know about MATLAB } \\
\text { \& SIMULINK }\end{array}$ & 5 & 10 \\
\hline 2 & Operations on Matrices & 6 & 6 \\
\hline 3 & $\begin{array}{l}\text { Generation of Signals } \\
\text { \& Sequences }\end{array}$ & 4 & 8 \\
\hline 4 & Operations on Signals & 5 & 10 \\
\hline 5 & $\begin{array}{l}\text { Convolution and } \\
\text { Correlation }\end{array}$ & 3 & 6 \\
\hline & & Total & 40 \\
\hline
\end{tabular}

The complete analysis of assessment marks obtained by the experimental set of 120 students for the first five interactive videos included in the Moodle LMS portal for the lab course "Basic Simulation" is depicted by the graph shown in the Fig. 6.

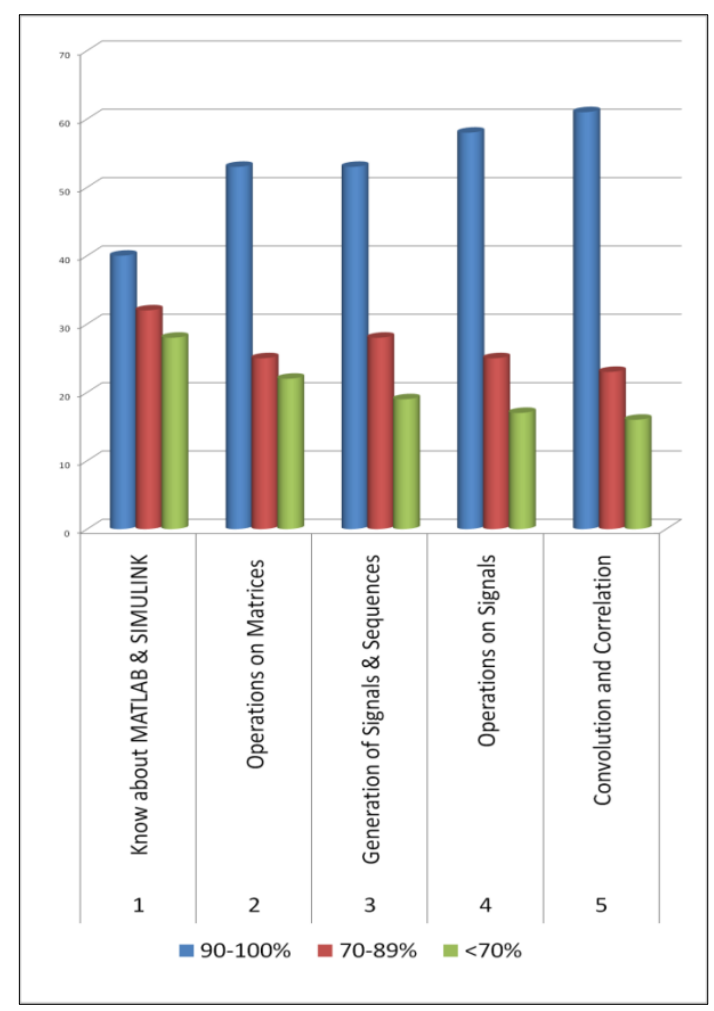

Fig. 6 Analysis of Direct Assessment Marks 
It has been observed that the learners have shown a great improvement in the marks scored from the first video to the fifth video. This improvement directly shows the impact of the interactive video content in the learning mechanism, driving the deeper student engagement.

Interactive videos using $\mathrm{H} 5 \mathrm{P}$ are made available in other courses. As an example few courses are "Electronic Devices and Circuits Lab" and "Digital System Design Lab". Few interactions for the above said labs are shown in Fig. 7 and Fig. 8 .

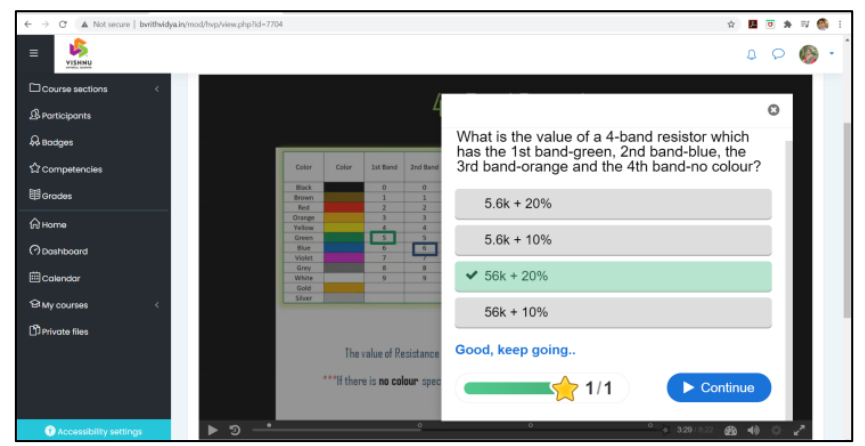

Fig. 7 Example interaction - finding the resistor value using colour codes in the introduction video on components in "Electronic Devices and Circuits" Lab

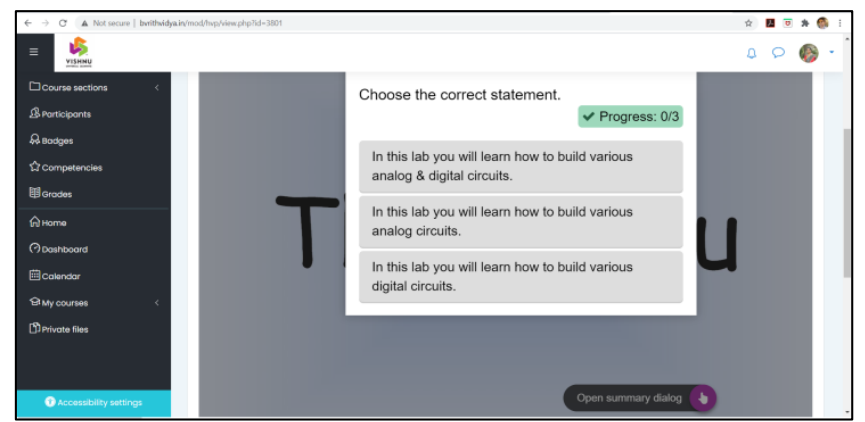

Fig. 8 Example interactions as a part of Summary task - in the introduction video in "Digital System Design" Lab

\section{Qualitative study - Interactive Videos}

The motive of this qualitative study is to collect the learner opinion about the idea of using interactive videos as a part of content delivery in the LMS which in turn is useful for enhancing the interactive videos creation by the teacher and also hence improving the learning and retention rate of information collected during the study.

Table 2. Qualitative Study - Likert Scale Questions

\begin{tabular}{|c|l|}
\hline $\begin{array}{c}\text { Question } \\
\text { No. }\end{array}$ & \multicolumn{1}{c|}{ Question } \\
\hline 1 & $\begin{array}{l}\text { Your Interaction with the video is clear and } \\
\text { Understandable }\end{array}$ \\
\hline 2 & $\begin{array}{l}\text { Interactive Videos improves your individual's class } \\
\text { performance }\end{array}$ \\
\hline 3 & I find the interactive videos are user friendly \\
\hline 4 & $\begin{array}{l}\text { As a learner, I am satisfied with the ease of } \\
\text { navigating the interactive video }\end{array}$ \\
\hline
\end{tabular}

\begin{tabular}{l|l}
5 & $\begin{array}{l}\text { Using the interactive videos I am completely } \\
\text { engaged in learning the course }\end{array}$
\end{tabular}

Since the current semester is going on, a small set of Likert scale questions (Clément Benkada and Laurent Moccozet, 2017) were sent to the same set of 120 students of II year electronics and communication engineering through Google forms to record the satisfaction rate in using interactive videos. The questions are listed in Table 2 and Fig.9 shows the Google form shared to the students.

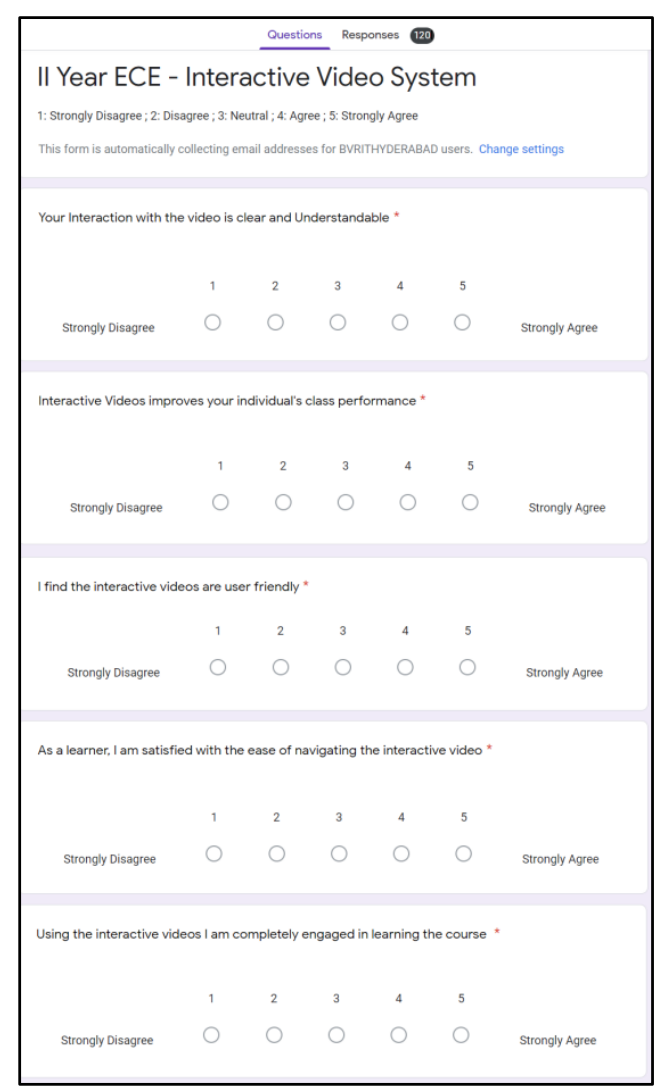

Fig. 9 Qualitative Study - Likert Scale Questions - Google Form

The Likert scale questions need to be responded by the students on a 5 point scale defined as 1: Strongly Disagree, 2: Disagree, 3: Neutral, 4: Agree, and 5: Strongly Agree. The responses of all the set of 120 students for the Likert scale questions were recorded and are shown graphically in the Fig.10 through 14. 


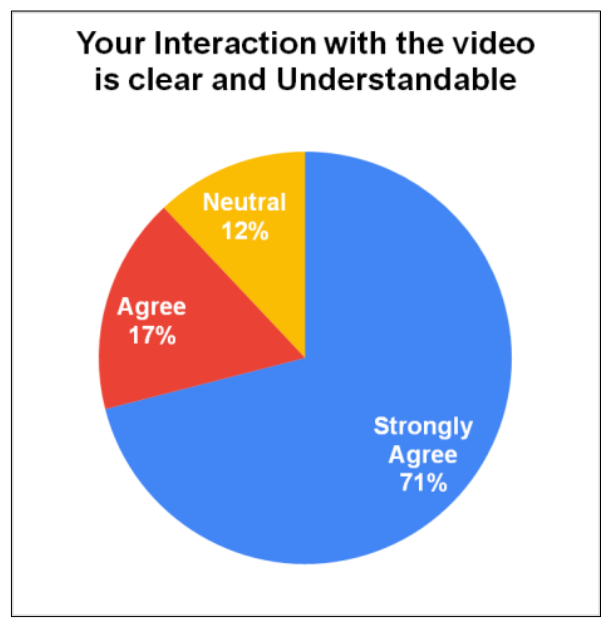

Fig. 10 Qualitative Analysis result for Question No.1

This qualitative analysis indicates that the activity of adding interactive video content to the LMS for content delivery is technically approachable for the students and makes them more engaging.

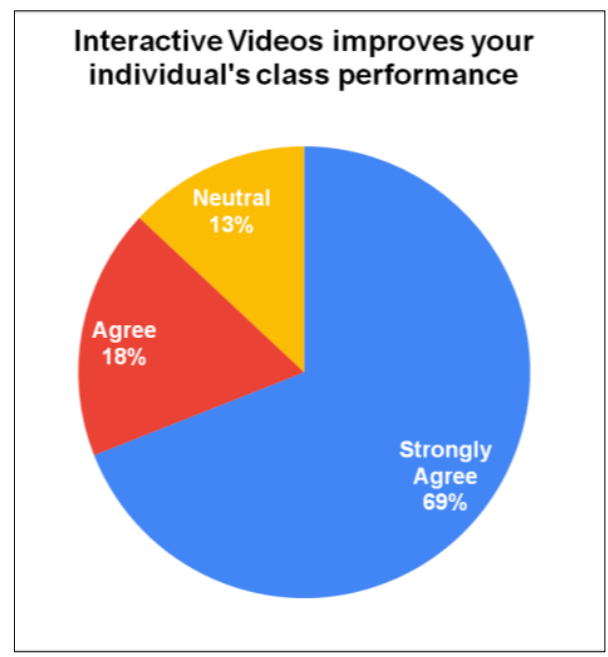

Fig. 11 Qualitative Analysis result for Question No.2

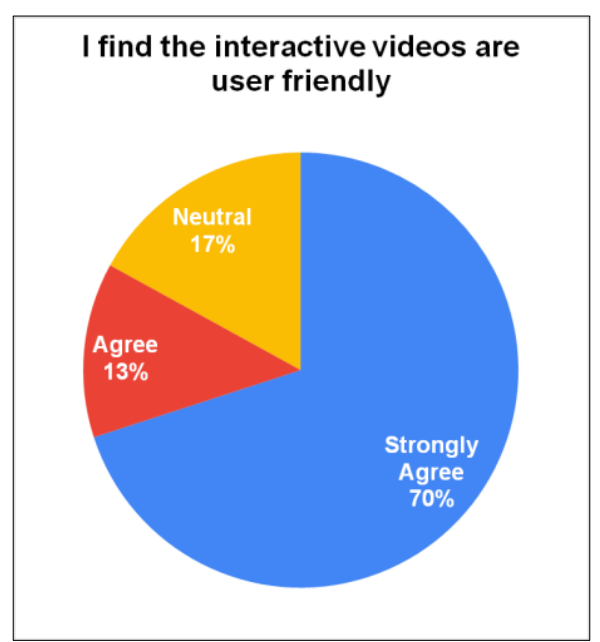

Fig. 12 Qualitative Analysis result for Question No.3

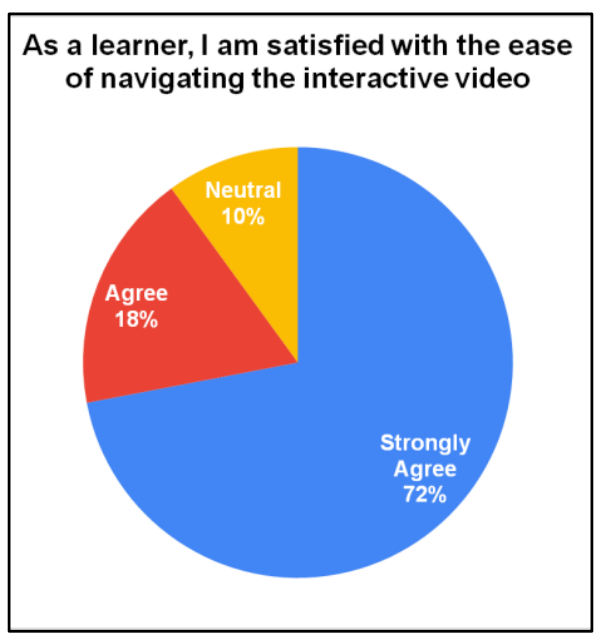

Fig. 13 Qualitative Analysis result for Question No.4

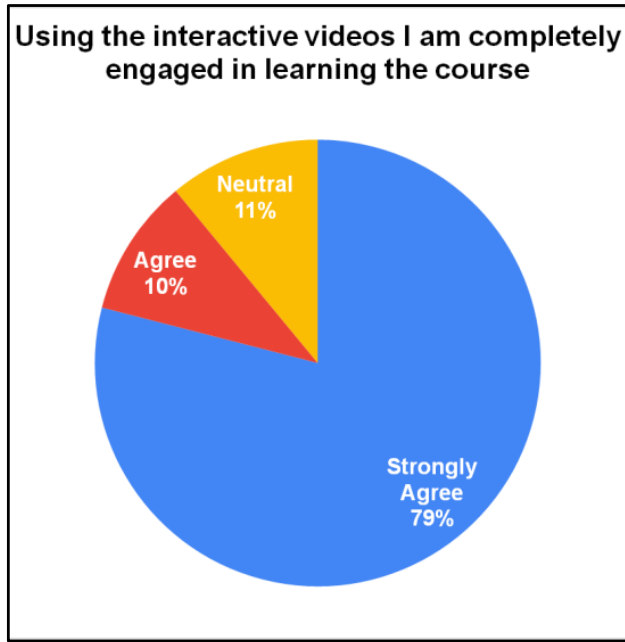

Fig. 14 Qualitative Analysis result for Question No.5

This kind of learners' mind-set towards interactive video content would certainly encourage the teachers to prepare the valuable content in LMS. As per the SAGE Graphics Experiment, using graphics in instructional and educational videos there is a sustainment in the scope of student's concentration levels (Michael Carmichael et al., 2018) and adding interactions to such videos hopefully have a greater impact on the improvement of student's cognitive skills. This study supported the belief that the significance of interactive e-learning depends on various aspects with the inclusion of learners, teachers, technological updates, production ethics, and content (Dongsong Zhang et al., 2006). In addition, considering students' engagement and disengagement indicators (Melissa Bond et al., 2020) could help the analysis and define the new student engagement dimension.

\section{Conclusions}

In this paper, the design of interactive videos using $\mathrm{H} 5 \mathrm{P}$ plug-in in Moodle LMS is detailed and the experimental study on impact of adding interactions to educational 
videos on student engagement and learning was performed. The study results supported our abstraction on the positive effects of interactive videos. The outcome of quantitative and qualitative analysis performed encourages the facilitators to support such learner-centric interactive videos. Finally this study recommends the use of interactive videos in presenting the course content helping to drive deeper engagement in learners and transform the ways a learner processes the knowledge attained.

\section{Acknowledgement}

We are very grateful to the Principal and Management of Sri Vishnu Educational Society for providing us various opportunities to learn new tools required for blended learning, nominating us to attend the a six week IUCEE Online Teaching Course and also encouraging us to take part in the Eighth International Conference on Transformations in Engineering Education and connect engineering educators from all over India.

\section{References}

[1] Orna Farrell and James Brunton. (2020) A balancing act: a window into online student engagement experiences. Int $J$ Educ Technol High Educ 17, 25.

doi: 10.1186/s41239-020-00199-x

[2] Brenda Juárez Santiago, JuanManuel Olivares Ramírez, Juvenal Rodríguez-Reséndiz, Andrés Dector, Raúl García García, José Eli Eduardo González-Durán, and Fermín Ferriol Sánchez. (2020) Learning Management SystemBased Evaluation to Determine Academic Efficiency Performance, Sustainability, 12, 4256.

doi: $10.3390 /$ su 12104256

[3] Sonia Wilkie, Ghaith Zakaria, Tania McDonald, Rosy. B.Borland. (2018) Considerations For Designing H5P Online Interactive Activities, ASCILITE 35th International Conference on Innovation Practice and Research in the Use of Educational Technologies in Tertiary Education, 543-549.

[4] Michail N. Giannakos, Letizia Jaccheri and John Krogstie. (2016) How Video Usage Styles Affect Student Engagement? Implications for Video-Based Learning Environments. Y. Li et al. (eds.), State-of-the-Art and Future Directions of Smart Learning, Lecture Notes in Educational Technology, 157-163.

doi: 10.1007/978-981-287-868-7_18

[5] L N Amali, N T Kadir, and M Latief. (2019) Development of e-learning content with H5P and iSpring features, Journal of Physics: Conf. Series, 1387.

doi: 10.1088/1742-6596/1387/1/012019

[6] Stefan Richtberg, Raimund Girwidz. (2019) Learning Physics with Interactive Videos - Possibilities,Perception, and Challenges, Journal of Physics: Conf. Series, 1287.

doi:10.1088/1742-6596/1287/1/012057
[7] Line Kolås. (2015) Application of interactive videos in education, International Conference on Information Technology Based Higher Education and Training, 1-6. doi: 10.1109/ITHET.2015.7218037.

[8] Marjolein E. Haagsman, Karin Scager, Johannes Boonstra and Margot C. Koster. (2020) Pop-up Questions Within Educational Videos: Effects on Students' Learning. J Sci Educ Technol 29, 713-724. doi: $10.1007 / \mathrm{s} 10956-020-09847-3$

[9] Clément Benkada and Laurent Moccozet. (2017) Enriched Interactive Videos for Teaching and Learning, International Conference on Information Visualisation (IV), 344-349.

doi: $10.1109 / \mathrm{iV} .2017 .74$

[10] Michael Carmichael, Abigail-Kate Reid and Jeffrey D. Karpicke (2018). Assessing the Impact of Educational Video on Student Engagement, Critical Thinking and Learning: The Current State of Play. A SAGE Whitepaper, SAGE Publishing, 1-21.

[11] Dongsong Zhang, Lina Zhou, Robert O. Briggs, Jay F. Nunamaker, (2006) Instructional video in e-learning: Assessing the impact of interactive video on learning effectiveness, Information and Management Journal, 43(1), $15-27$.

[12] Melissa Bond, Katja Buntins, Svenja Bedenlier, Olaf Zawacki-Richter and Michael Kerress. (2020) Mapping research in student engagement and educational technology in higher education: a systematic evidence map. Int J Educ Technol High Educ 17, 2. doi: 10.1186/s41239-019-0176-8 